\title{
PAZ RELIGIOSA, LIBERTAD RELIGIOSA: LA APUESTA POR EL PACIFISMO DE PEDRO XIMÉNEZ EN EL DIALOGUS DE PACE (1579)
}

\author{
POR \\ IGNACIO J. GARCÍA PINILLA ${ }^{1}$ \\ Universidad de Castilla-La Mancha
}

\section{RESUMEN}

Pedro Ximénez (Petrus Ximenius, 1524-1595) es un personaje muy poco conocido actualmente, a pesar del gran prestigio del que gozó en vida. La reciente identificación del anónimo Dialogus de pace como obra suya permite estudiar su avanzada postura ante el habitual uso de la coerción para imponer la unidad religiosa, en concreto en el marco de la conferencia de paz de 1579 en Colonia. En esta obra, marcadamente pacifista, incide en los conceptos de amnistía, consenso y restitución, con un desarrollo que puede ponerse en parangón con las aportaciones de otros españoles sobre el mismo asunto, como las de Fadrique Furio Ceriol.

PALABRAS CLAVE: tratados de gobierno; Pedro Ximénez; Fadrique Furio Ceriol; Países Bajos; pacifismo; Guerra de los Ochenta Años.

\section{RELIGIOUS PEACE, RELIGIOUS FREEDOM: THE COMMITMENT TO PACIFISM IN PEDRO XIMÉNEZ DIALOGUS DE PACE (1579)}

\begin{abstract}
Pedro Ximénez (Petrus Ximenius, 1524-1595) is a very little known figure now, in spite of the great prestige that enjoyed in life. The recent identification of the anonymous Dialogus de pace as his work allows us to study his advanced position in relation to the use of coercion to impose religious unity, specifically in the framework of the 1579 peace conference in Cologne. In this work, notably pacifist, Ximénez stresses the concepts of amnesty, consensus and restitution, with a development that can be compared with the contributions of other Spaniards on the same subject, as those of Fadrique Furio Ceriol.
\end{abstract}

KEY WORDS: Treatises on government; Pedro Ximénez; Fadrique Furio Ceriol; Low Countries; Pacifism; Eighty Years War.

Cómo CITAR ESTE ARTículo / CITATION: García Pinilla, I. J. 2018. «Paz religiosa, libertad religiosa: la apuesta por el pacifismo de Pedro Ximénez en el Dialogus de pace (1579)». Hispania Sacra 70, 141: 39-50. https://doi.org/10.3989/hs.2018.004

Recibido/Received 09-05-2017

Aceptado/Accepted 09-06-2017

\section{¿QUIÉN ES PEDRO XIMÉNEZ?}

Solo en fecha relativamente reciente, hace unos cincuenta años, la figura de Pedro Ximénez (Petrus Ximenius) comienza a aparecer en los estudios sobre protestantes y disidentes españoles. Quien Ilamó definitivamente la atención sobre él fue Juan Ignacio Tellechea Idígoras, en un estudio donde publicaba un documento que obligó a modificar muchas presunciones sobre la actitud doctrinal de un buen número de intelectuales españoles de mediados del siglo XVI. ${ }^{2}$ En

1 ignacio.gpinilla@uclm.es / ORCID iD: http://orcid.org/00000003-2468-0285

2 En su artículo Tellechea Idígoras 1963: 21-45. Posteriormente, matizaría algunos aspectos en ibídem 2000: 133-156. La figura de Ximenius está necesariamente presente en la bibiografía científica desde su artículo, Tellechea reproducía y analizaba un extenso memorial de 1558 en el que fray Baltasar Pérez denunciaba un grupo de españoles que se solían reunir en torno a Pedro Ximénez, al que consideraba el cabecilla y tildaba de «heresiarca». No fue la única vez que sufrió denuncias por motivos religiosos, pues en fecha no muy posterior fue apresado y trasladado a Lovaina para que se sometiera al dictamen teológico de la universidad, que finalmente lo declaró libre de todo cargo. ${ }^{3}$ A pesar de esta situación en el límite, Ximénez nunca dejó el catolicismo.

el siglo XVIII, pero predominan la mención de pasada, la escasez de datos, la dispersión y una sensación generalizada de desconocimiento.

3 Así se desprende de una carta de fray Lorenzo de Villavicencio a Felipe II, quizá de octubre de 1565: [enumerando sus méritos en favor de la religión] «Truge a Pero Gimenez de Colonia, hombre doctisimo, y hice 
Tras el artículo de Tellechea, el siguiente avance relevante se debió a Carlos Gilly, gracias al aporte de referencias de archivo desconocidas y al acarreo de información de epistolarios y otras fuentes dispersas. Gilly trazó un panorama de las relaciones de Ximénez, entre las que destacó las del mercader calvinista Marcos Pérez y los humanistas Theodor Zwinger y Karel Utenhovius. A la vez, llamó la atención sobre la obra a cuya composición dedicó Ximénez tantos años, que fue largamente esperada en círculos irenistas y de la que no conservamos ninguna copia: la Demonstratio Christianae et Catholicae veritatis. ${ }^{4}$ Por su parte, Ron Truman le dedicó dos estudios centrados en su presunta disidencia y en sus relaciones en los Países Bajos, especialmente con Robert de Berghes, Dominique Lampson y Laevinus Torrentius, primer obispo de Amberes. ${ }^{5}$ Sin embargo, es el trabajo de Peter Arnold Heuser el que ha supuesto recientemente un avance más notorio en el conocimiento sobre Ximénez, por lo que será reiteradamente usado a continuación. ${ }^{6}$

El progreso de nuestro conocimiento sobre él ha sido lento, pero sostenido. Dificultaba la investigación biográfica la dispersión geográfica del personaje, que exige competencia en bibliografía latina, holandesa, belga, española, italiana y alemana, a menudo local. Por otra parte, el avance del conocimiento sobre sus ideas chocaba con la pérdida de toda su obra escrita, salvo un cierto número de cartas, tanto impresa como inédita. ${ }^{7} \mathrm{El}$ avance ha sido tal que recientemente el profesor P. A. Heuser ha logrado identificar como obra de Pedro Ximénez el Dialogus de pace sobre el que versa este artículo. ${ }^{8}$ Su argumentación se basa en una carta tardía (02/01/1613) de Heinrich Botter, un profesor de Medicina de Colonia y amigo de Matal, a su colega Galenos Weyer, en la que afirma que Jean Matal le contó que el autor del Dialogus de pace era obra de Ximénez. ${ }^{9}$ Además, Heuser confirma que Matal, quien mantenía con Ximénez una relación estrechísima en Colonia, fue esencial en la difusión del libro; incluso en la biblioteca universitaria de Groningen se conserva un ejemplar dedicado personalmente por Matal a Laevinus Torrentius. Todo ello otorga coherencia a la afirmación de Botter. Gracias a la propuesta de Heuser, es la primera vez que podemos someter a estudio las ideas de un escrito de este humanista.

Pedro Ximénez nació en Middelburg en 1524 en el seno de la familia de comerciantes andaluces Ximénez de León, instalada allí desde al menos dos generaciones antes. ${ }^{10} \mathrm{~A}$

que se sugetase al inquisidor Tileto y a la facultad teologa de Lovayna, y pasase por su sentencia», reproducida en Gachard 1851: vol. II, XX.

4 Gilly 1985: 426-427. Gilly anuncia la presencia de información nueva sobre esta obra en un artículo en preparación sobre Castellio y España.

5 Truman 1993: 247-263, 254-256; ibídem 1998: 367-386.

6 Heuser 2003: 176-208.

Aunque requiere añadir información por las aportaciones de la investigación posterior sobre Ximenius, sirve como aproximación un estudio que traza un primer elenco de sus cartas y un repertorio de menciones sobre él, García Pinilla 1997: 179-207.

8 Heuser 2013: 387-411. En realidad, ya se señala en Heuser 2003: 364-365, pero la argumentación en favor de la autoría es mucho más sólida en el artículo de 2013.

9 El original de la carta se conserva en la Biblioteca Nacional de Francia, col. Dupuy 348, f. 204.

10 A la importancia de esta familia en Middelburg se refiere Fagel 2015: 339-352, esp. 344 y 346. No es descartable que la famosa uva Pedro Ximénez deba su nombre a esta familia, en la que se reitera el veces se le menciona como lusitano, quizá por confusión debida a que su familia figura a veces en la nación lusitana en Middelburg, por motivos de oportunidad comercial; o bien por confusión con los Ximenes (de Aragón), otra poderosa familia de comerciantes, en este caso portugueses, igualmente asentada en los Países Bajos. En fecha indeterminada, pero sin duda siendo un muchacho, Pedro Ximénez se trasladó a Salamanca para ser paje del obispo, al que le unía algún tipo de relación. ${ }^{11}$ Las fuentes indican que continuó la peregrinatio de sus estudios en Bolonia y Padua, antes de trasladarse a París, aunque no se ha hallado testimonio ninguno de su presencia en esas ciudades. Puede descartarse, sin embargo, la hipótesis alguna vez sugerida sobre su identidad con el Pedro Jiménez que estuvo en Roma a las órdenes de dos embajadores españoles sucesivos, Juan de Vega y Diego Hurtado de Mendoza; este último era Pedro Jiménez del Rincón y continuaba su actividad como agente en Sicilia cuando el nuestro era propuesto en Lovaina para ocupar una cátedra de derecho en 1557, aunque no poseyera los grados pertinentes. ${ }^{12}$

Consta la presencia de Ximénez en Lovaina desde mediados de la década de 1550. Allí encabezaba un conventículo de españoles con posturas doctrinales consideradas inquietantes por los elementos más tradicionales. ${ }^{13}$ Pero Ximénez solo ocupó la mencionada cátedra unos meses, los últimos de su estancia en esa ciudad: optó por apartarse del ambiente de Lovaina, enrarecido contra él, y se trasladó a Lieja, donde fue acogido como capellán por el obispo Robert de Berghes. ${ }^{14}$ Secretario de este último era Dominique Lampson, quien se convirtió a partir de entonces en protector de Ximénez. Las denuncias interpuestas contra él en Lovaina siguieron su curso, pero finalmente todas ellas fueron desestimadas, no sin incluir una reprensión contra él por la excesiva libertad de sus palabras.

A comienzos de la década de 1560 se documenta su relación con el Jean Matal, así como sus vivas relaciones con Georg Cassander y el círculo irenista de Colonia. Cuando murió el obispo de Lieja, en 1564, Ximénez dispuso de más libertad de movimientos, lo que se refleja en las largas temporadas que pasaba en Amberes (donde vivía parte de su familia) y, sobre todo, en Colonia, junto a Cassander, con quien compartía ideal irenista. ${ }^{15}$ En 1570 fue contratado por la universidad de esta última ciudad como profesor de filosofía, aunque solo ocupó el puesto cuatro años, hasta 1574; enton-

nombre de pila Pedro. También reúne datos adicionales sobre la familia de Ximénez, Gilly (e. p).

11 Miraeus 1649: 154-155: «...adolescens missus est Salmanticam ad eius loci Episcopum, qui cognatione opinor aliqua vel affinitate ipsum attingebat». En cambio, no parece que pueda ser él, pero quizá sí un pariente suyo, el Petrus Petri Midelburgensis matriculado en Lovaina en 1530, cf. Schilling 1961: vol. 4, 543. El obispo aludido debía de ser Luis Cabeza de Vaca, que ocupó esa sede entre 1530 y 1537.

12 Díaz Rodríguez 2016: 51-78, 72. Para la presencia de Páez en Lovaina en 1557, García Pinilla 1997: doc.1.

13 Cf. Tellechea Idígoras 1963: 23-25 y 36-39. Por otra parte, un Petrus filius Petri Medelburgensis se matriculó en Lovaina, quizá por segunda vez, en enero de 1557 (cf. Schilling 1961: 543). Un buen resumen de esa etapa lovaniense de Ximénez puede leerse en Truman 1999: 35-37.

14 Una relación sumaria de todos estos acontecimientos, con bibliografía, puede leerse en Truman 1993: 254-256.

${ }_{15}$ Cf. Puraye 1950: 26-27. 
ces le sucedió Bonaventura Vulcanius. ${ }^{16} \mathrm{~A}$ partir de entonces Ximénez se dedicó fundamentalmente a la redacción de su magnum opus, que no nos ha llegado: Demonstratio Christianae et Catholicae veritatis. En la correspondencia de la época se observa cómo la expectación en torno a ella iba en aumento y cómo algunas secciones ya redactadas circulaban entre círculos selectos de humanistas y altas jerarquías civiles y eclesiásticas, tanto católicas como reformadas. También se detectan algunos movimientos para buscar apoyo económico para su impresión, tarea costosa a causa de su amplitud. En torno a 1592 la Demostratio estaba casi terminada, pero la decrepitud de Ximénez hacía temer que quedara sin culminar. ${ }^{17}$ De hecho ni siquiera sabemos si fue así: Ximénez murió en el verano de 1595, y entre sus allegados cesa entonces cualquier referencia a su obra. Disponemos de un testimonio casi contemporáneo y ajeno a sus amistades sobre el asunto:

Illum Dominicus Lampsonius [...] commendabat. Moliebatur opus grande sub manibus, maximis multorum impendiis, qui hominis laborem auidissime praestolabantur. Spes complurium erat Christianae Reip. proficuum fore. Caeterum secus accidit. Quippe lectus a Catholicis liber ac diligenti examine, quae e nouis suspectarum opinionum lacunis, tum alieno ab Ecclesia sensu deprompta consarcinauerat, prudenter expensis, tenebras citius quam lucem mereri iudicatus est. +Eum ${ }^{+}$ Theodorus Riphan [...], Vlenbergius item et quos illi sacra Coloniensium facultas Theologica collegas adiunxerat, censuerunt, qui productis dogmatibus ne vulgaretur authores fuere. Eadem censura ad Serenissimum Gulielmum Bauariae ducem, Antistes Antwerpianus Reuerendissimus Dominus Laeuinus Torrentius idem opus notauit, authorem iam graui senio laborumque mole fractum, ob praeclaras animi dotes pietatemque ac vitam innocenter exactam, insigni elogiio prosecutus. Exemplar manuscriptum amplissimo Senatui traditum in urbis archaeo adseruatur. ${ }^{18}$

16 La inscriptio "Ximenio» en la minuta de una carta de Bonaventura Vulcanius (De Vries de Heekelingen 1923: 170) ha generado el error de suponer que nuestro Petrus Ximenius fue bibliotecario en 1576, cuando sin duda no es una carta dirigida a Colonia, sino a Viena, quizá al jesuita homónimo. La relación de Cassander con la búsqueda de la paz ha sido estudiada recientemente en Van De Schoor 2011: 127-147.

17 Se describe todo este asunto en Puraye 1950: 27-29. En cuanto a los intentos de publicarla, hay una carta de D. Lampson a William Cecil, el poderoso Lord Burghley, de octubre de 1583, en la que pedía su ayuda para la impresión, $c f$. British Library, Lansdowne ms. 38, n. 56.

18 Meshov 1638: 50-51: "[a Jiménez] lo recomendaba Dominique Lampson [...]. Tenía entre manos una importante obra, gracias a los enormes gastos de muchas personas que esperaban con gran ansiedad el resultado de su trabajo. La esperanza de muchos era que sería de provecho para la Iglesia, pero resultó de manera diferente. De hecho, se consideró que el libro, una vez leído por los católicos y tras examen atento y tras valorar prudentemente los puntos de que estaba cargado, extraídos de nuevas deficiencias en opiniones sospechosas y en sentido ajeno a la Iglesia, merecía las tinieblas, antes que la luz. Theodor Riphan, así como Ulenberg y los que habían sido añadidos como colegas por la facultad de teología de Colonia, opinaron contra él, al instar con los pareceres que ofrecieron que no se publicara. Con idéntica opinión, dirigida al serenísimo Guillermo, duque de Baviera, notó la misma obra el reverendísimo Levino Torrencio, obispo de Amberes, aunque honrando al autor, que sufría por la vejez y gran cantidad de males, con una singular alabanza en razón de sus singulares cualidades de espíritu, de su piedad y de una vida vivida en la inocencia. La copia manuscrita entregada a la corporación se conserva en el archivo municipal». La opinión es relativamente interesada, pues conocemos por otra fuente el escrito de Torrencio y se muestra favorable a la publicación, aunque aplica una fórmula de reserva por su escasa ciencia teológica, cf. Torrencio 2007: LV-LVI.
Después de su peregrinatio juvenil, la vida de Ximénez se repartió principalmente entre Lovaina, Amberes, Lieja y Colonia, ciudad en la que se asentaría de modo definitivo, sobre todo a raíz de la llegada de familiares suyos, exiliados de los Países Bajos: los Ximénez, Palma, Hiniosa (o Hinojosa), Pérez y López de Villanova. ${ }^{19}$ Nunca perdió, por tanto, sus raíces, de modo que la situación de violencia y desorden en los Países Bajos le afectaba en lo más íntimo y amenazaba con destruir todo el fundamento en que se apoyaba su familia.

\section{CONFERENCIA DE PAZ DE COLONIA, 1579}

En 1579, la situación de revuelta en los Países Bajos se prolongaba ya durante trece años. ${ }^{20}$ La gestión de la gobernadora Margarita de Austria en el annus mirabilis de 1566, con la iconoclastia calvinista, y la llegada del Duque de Alba como su sucesor en 1567 significaron el comienzo de una rebelión que condujo a un conflicto permanente. La opción militar no parecía garantizar una salida de la situación, de modo que el siguiente gobernador, Luis de Requesens y Zúñiga, nombrado en 1573, llegó con el objetivo de tantear una salida mediante la negociación. ${ }^{21}$ Sin embargo, la pretensión real de regresar a la situación previa al conflicto, sin concesiones religiosas, hacía inviable ese intento, a la vez que los amotinamientos de las tropas por los impagos multiplicaban la desconfianza por parte de las provincias del norte. Con la muerte de Requesens en 1576, fue nombrado gobernador don Juan de Austria, el hermanastro de Felipe II, quien demoró varios meses su venida y, nada más llegar, recibió la noticia del terrible saqueo de Amberes por parte de las tropas españolas (4 de noviembre de 1576). Si bien los delegados de los Estados Generales y de los rebeldes estaban reunidos desde octubre y ya existía un acuerdo, la consternación y hartazgo de unos y otros ante los pillajes de los soldados condujo a la ratificación, tan solo cuatro días después del saqueo, de la Pacificación de Gante. Por ella los representantes de las provincias, tanto leales como rebeldes, se unían para reclamar la salida de las tropas españolas, la amnistía para los rebeldes, la capacidad legislativa de los Estados Generales y la restauración de los privilegios; todo ello, reconociendo la autoridad real y el culto católico. ${ }^{22}$ Desde el punto de vista de la convivencia religiosa, entre los veinticinco artículos de la Pacificación resultaban significativos el quinto, que ordenaba la suspensión de la legislación carolina y de los decretos del Duque de Alba en materia de herejía, y el duodécimo, que restituía los bienes de personas condenadas por motivos religiosos. ${ }^{23}$ Mediante el Edicto Perpetuo, don Juan de Austria reconoció este acuerdo en enero de 1577.

Este acuerdo no supuso, sin embargo, una pacificación real, pues la desconfianza entre ambas partes provocó el incumplimiento de los acuerdos. De hecho, el alejamiento

19 En este aspecto es imprescindible la aportación de Heuser 2003: 179-188.

20 Se describe la situación en Schepper 2002: vol. 1, 325-354.

21 Para una visión de conjunto sobre Requesens, cf. Schepper 1998: 157-167.

22 Koenigsberger 2001: 272.

23 Goosens 1997: 1, 121. 
de las tropas españolas fue aprovechado por los rebeldes para avanzar posiciones. En respuesta, don Juan de Austria ordenó el regreso de los militares, que llegaron a finales de 1577, bajo el mando del duque de Parma, Alejandro Farnesio. ${ }^{24}$

La muerte inesperada del gobernador en octubre de 1578 podría haber causado un nuevo vacío de poder (que tan desastroso había resultado dos años antes), por lo que se llevó a cabo una sucesión rápida y provisional en la persona de Farnesio. La acción de este se movió decididamente en busca del apaciguamiento, pero sin renunciar a la fuerza militar como garantía de su propia posición. A la política de reconciliación de ciudades y nobles se añadía la tendencia a buscar una pacificación general, al estilo de la fallida Pacificación de Gante. ${ }^{25}$ El comienzo del año 1579 había sido testigo de un éxito diplomático de Farnesio, cuando las provincias del sur que habían apoyado a Guillermo de Orange regresaron a la obediencia de Felipe II en la Unión de Arras. La contrapartida fue que apenas dos semanas después las provincias rebeldes establecieron la Unión de Utrecht, mediante la que rechazaban definitivamente la autoridad filipina, con un carácter abiertamente calvinista.

En esta situación, en mayo de 1579 comenzó una conferencia de paz en Colonia, auspiciada por el emperador Rodolfo II y con la mediación de comisarios imperiales, en la que las dos partes en conflicto (la Corona española y las provincias rebeldes del norte) debían intentar alcanzar un acuerdo que permitiera la pacificación definitiva de los Países Bajos. ${ }^{26}$ La protección de la libertad y la autoridad de los Estados Generales constituían temas centrales en las negociaciones. La propuesta de la parte mediadora incluía parte de las reclamaciones de los rebeldes, a la vez que otorgaba a Felipe II la restauración de su autoridad. En concreto, se proponía volver a la situación política previa al conflicto; el rey Felipe debía respetar y restaurar todos los privilegios y libertades; quedarían establecidos los principios de la Pacificación de Gante y del Edicto Perpetuo; todas las provincias reconocerían la autoridad real de Felipe II; el culto protestante se permitiría en algunas ciudades-refugio de Holanda y Zelanda; la religión romana sería la oficial. ${ }^{27}$

A la llegada de la delegación de los Estados Generales a Colonia, el 18 de mayo de 1579, esta presentó como exigencia el reconocimiento por parte del rey de los derechos y privilegios, además del ius resistendi, un statu quo en cuestiones de fe (que conllevaba, de hecho, una "paz religiosa» con libertad de culto), el reconocimiento del archiduque Matías de Habsburgo como gobernador y el retorno de todos los exiliados; todas ellas se presentaban como consecuencias de la Pacificación de Gante. ${ }^{28}$ Ahora bien, a esa delegación solo se le reconocía un mandato de seis semanas.

Inmediatamente quedó claro que las posiciones de ambas delegaciones estaban muy separadas y que la capacidad de transacción de unos y otros era corta. Aun así, las negociaciones continuaban y, por ejemplo, la propuesta

\footnotetext{
24 Para una perspectiva general sobre la actuación de este último, cf. Losada Málvarez 2007.

25 Cf. Janssens 1993: 251-278; Stensland 2012: 90-91.

26 Se describe la situación en Arndt 1998: 161-183, 169-179.

27 Cf. Van Gelderen 1992: 141.

28 Soen 2012: 139.
}

de la delegación real del 3 de junio contenía concesiones de cara a una amplia amnistía y a aceptar un nuevo gobernador «de la sangre real»; complementariamente, se reconocía a los protestantes un ius emigrandi de cuatro años, sin secuestro de la propiedad durante ese período. En ese momento crucial el magistrado de Amberes exigió, el 12 de junio, una paz religiosa más amplia; con ello, quedó patente que el punto clave de la negociación sería la cuestión religiosa. La propuesta del 18 de julio todavía fue más amplia, pues incluía el reconocimiento temporal del calvinismo en lugares de Zelanda y Holanda, así como la desaparición de los placards. Guillermo de Orange se mostró opuesto a un acuerdo así y, de hecho, los Estados Generales lo rechazaron. ${ }^{29}$ Por otra parte, las discrepancias internas entre los delegados reales eran fuertes, pues se percibía de modo muy diferente el efecto esperable de una paz religiosa, así como la calificación moral del acto en sí mismo.

La situación había llegado a un punto muerto, complicada además porque el plazo concedido por los Estados Generales había expirado ampliamente. En septiembre el duque de Terranova escribió a Madrid pidiendo el cese de las negociaciones. Aunque formalmente la conferencia, sin acuerdo, no se dio por acabada hasta noviembre, las expectativas de ambas partes se habían ido extinguiendo paulatinamente. Fue un golpe definitivo para los irenistas, deseosos de encontrar una via media que condujese a una pacificación mediante concesiones recíprocas. Entre ellos se contaban el jurista Jean Matal (Metellus) y su amigo Pedro Ximénez, ambos asentados en Colonia y que tantos desvelos habían dedicado a buscar el éxito de la conferencia. ${ }^{30}$ Así finalizaba el último intento de alcanzar la paz mediante negociaciones. La opción militar se impondría hasta la Paz de Westfalia.

\section{El Libro Dialogus de PACE}

En este ambiente de la conferencia de Colonia se publicaron, ya desde los meses previos, muchos tratados sobre el apaciguamiento, en los que frecuentemente los argumentos religiosos andaban mezclados con los políticos, sobre todo en la petición de la paz religiosa (religions vrede). Si bien no son calificables como obras de teoría política, el análisis de estas obras de circunstancias es imprescindible para comprender el desarrollo del pensamiento en torno a cuestiones como la tolerancia, la libertad de conciencia, la amnistía, la reconstrucción nacional, etc. ${ }^{31}$ Respecto a estas obritas es preciso señalar que, como expone van Gelderen, «la gran mayoría de los tratados sobre las propuestas de paz adoptaron una postura marcadamente negativa». ${ }^{32}$ Se trata, con pocas excepciones, de escritos de pocas páginas, casi siempre en neerlandés o en francés (a veces con versiones en ambas lenguas; en algún caso, en latín) y mayoritariamente partidarios de las provincias rebeldes. ${ }^{33}$

\footnotetext{
29 Soen 2012: 140-141.

30 Heuser 2003: 434-436.

31 Desde una perspectiva comunicativa, se examinan algunos de esos panfletos y carteles en Maczkiewitz 2005: 286-288.

32 Van Gelderen 1992: 141. Para un examen de algunos de ellos, $c f$. ibídem: 141-144.

33 La recopilación más completa de estos escritos sigue siendo la de Geurts 1956: 83-100.
} 
En este contexto se sitúa una obra de extensión notablemente mayor, que salió de la imprenta tres días después de que a miles de kilómetros se detuviera al secretario Antonio Pérez. El objeto de ese libro era contribuir a las negociaciones de paz, y de modo patente estaba dirigido a orientar la actuación de los delegados del rey. El título es el siguiente:

Viri pietate, virtute, moderatione, doctrinaque clarissimi dialogus de pace. Rationes, quibus Belgici tumultus, inter Philippum serenissimum et potentissimum Hispaniae Regem et subditos, hoc rerum statu, componi possint, explicans.

[s. I., s. i.] MDLXXIX, Calendis Septembris.

Existe otra edición, plenamente contemporánea, aparecida en Amberes en el mismo año con idéntico título, así como otra posterior, del siglo XVIII, incluida en los Analecta Belgica. ${ }^{34}$ Como se puede ver, la edición arriba citada carece de datos de imprenta, pero en los repertorios figura como impresa en Colonia por Gottfried von Kempen. ${ }^{35}$ La edición de Amberes, en cambio, sí identifica al editor: apud lacobum Henricium. ${ }^{36}$ La obra se publicó anónima, e incluso en la breve carta introductoria el impresor afirmaba desconocer la identidad de su autor, salvo el hecho de ser persona de reconocido prestigio. Fue Pieter Burman, en la edición de los Analecta Belgica citados en nota, quien atribuyó la obra a Kaspar Schetz von Grobbendonk (1513-1580), noble católico que participó en la conferencia de Colonia. ${ }^{37}$ Esa hipótesis triunfó y es habitual encontrar en los catálogos y repertorios el Dialogus de pace bajo su autoría. Como se ha dicho, recientemente P. A. Heuser ha demostrado que es obra de Ximénez, a cuyos sólidos argumentos cabe añadir todavía alguna evidencia más señalada por Gilly. ${ }^{38}$

Ante el problema de la prioridad entre las dos ediciones del mismo año, Heuser defiende que la de Colonia es anterior a la de Amberes, y para afirmarlo se basa en el argumento de que esta última incorpora en el texto la fe de erratas de Colonia y añade una guía de contenidos. Sin embargo, esta argumentación no es concluyente, pues la fe de erratas hubiera sido igualmente necesaria en la situación inversa y la guía podría haberse valorado como opcional. Es preciso analizar la cuestión con más detalle. Analizando las variantes entre las dos ediciones, se detecta que estas, una vez sanadas las erratas de Colonia con la fe, son escasas. Sin embargo, las divergencias observadas permiten afirmar que se trata de dos ediciones independientes, que proceden de

\footnotetext{
34 Analecticorum Belgorum pars prima 1772: 117-244.

35 Así se identifica en el VD16 1579: no 16, V.
}

36 Otra peculiaridad de la edición de Amberes es que, aprovechando un espacio libre al pie de la última página, se añade una curiosa calificación teológica, firmada por Walter van der Steeghen, canónigo de Amberes y cuya censura aparece en varios libros impresos en esa ciudad en torno a 1580. Para van der Steeghen el libro contiene afirmaciones contra la moral, pero se admite su publicación porque aporta ideas importantes sobre la pacificación. Es posible que el canónigo de Amberes compartiera el afán irenista de Ximenius y fuera su amigo, pues en una ocasión Levino Torrencio menciona la presencia de van der Steeghen junto a Ximenius en Colonia, $c f$. Torrencio 2007: 282.

$37 \mathrm{Si}$ bien es cierto que en su época el cardenal Granvela ya sospechaba de Kaspar Schetz como su autor, cf. Correspondance du Cardinal de Granvelle (1565-1586): vol. 8, 166 y 207.

38 Heuser 2013 y Gilly (e. p.). una fuente común, con toda probabilidad manuscrita. ${ }^{39}$ Es coherente con esto el hecho de que el encabezamiento de la citada fe de erratas de la edición de Colonia se disculpa por su gran número atribuyéndolas a la exemplaris obscuritate, lo que implica que fue compuesta a partir de una fuente de difícil lectura, algo difícilmente atribuible a un impreso, por lo que no parece que esas palabras puedan referirse a la edición antuerpiense.

Más aún, entre las variantes hay algunas pocas que manifiestan una intervención deliberada, con intención de alterar del sentido. Selecciono aquí dos, que ofrecen procedimientos diversos. En la página 115, I. 17-20 el texto, según $A$ y la fe de erratas de $C$, dice así:

...ut adversarii in his ditionibus maneant quidem et sint paulo potentiores iis qui nobis magis addicti videntur, ut propterea nobis sit difficilius et periculosius, funestum, si maxime velimus renovare bellum.

Ahora bien, $\mathrm{C}$ tiene impreso sint non paulo y nobis longe sit, que no son calificables como erratas, sino como un estadio de redacción previo, sobre el que se ha intervenido con el objeto patente de suavizar el contenido. La coincidencia de la fe de erratas con la edición de Amberes parecería abogar en favor de la prioridad de la de Colonia, que ofrecería entonces la redacción más antigua. No obstante, el segundo ejemplo muestra un panorama diverso que debe tenerse en cuenta antes de emitir un parecer. En efecto, en la página 116, I. 8-9 se lee: "A: Calvinianorum longe maiorem quam nostram in his ditionibus futuram potentiam».

En este caso, la fe de erratas no coincide con A, pues la fe propone omitir longe (aparte de añadir un nuevo error, Calvininorum). Por su parte, la edición de Colonia, antes de corregir, leía así: «C: Calvinianorum longe futurum maiorem quam nostram in his ditionibus potentiam».

Se trata, por tanto, de dos variantes que intentan subsanar tentativamente un pasaje de incierta lectura en C. A falta de un examen más detallado de toda la obra, parece que ambas ediciones no guardan entre sí una relación de filiación, sino que proceden de una fuente común, seguramente un manuscrito usado en la edición de Colonia y que, habiendo sufrido algunos retoques durante el proceso editorial, volvió a ser usado para la edición de Amberes. Existe, por tanto, una prioridad temporal de la edición de Colonia, pero esto no implica su prioridad desde el punto de vista crítico. Ahora bien, como se ha dicho, en líneas generales la edición de Amberes suele presentar mejores lecturas que la de Colonia. Es la que usamos aquí.

\section{ANÁLISIS DEL CONTENIDO}

El libro presenta una disposición continua del texto que no facilita la percepción del proceso argumentativo. De hecho, para la edición de Amberes se preparó una guía de contenidos, con 67 puntos numerados consecutivamente y

39 Se presenta aquí solo una muestra. Ejemplos de errores exclusivos de la edición de Amberes (cuya numeración de páginas y líneas usaré sistemáticamente): página 12, línea 10: concedenda C[olonia] en fe de erratas: concedendas A[mberes]; página 117, línea 3: pacem C: pacis $\mathrm{A}$. Ejemplos de errores exclusivos de la edición de Colonia: página 18, línea 4 commodae A: commode C; página 113, línea 19: praelatos A: privatos $\mathrm{C}$. Por tanto, ninguna es la base para la otra, pues no se transmiten los respectivos errores. 
que pretendían servir de orientación para quien tomara el libro entre sus manos. Ahora bien, tal guía no se atiene a la estructura real del contenido, sino que parece corresponder a un lector apresurado, quizá el corrector de imprenta, que anotó lo que le llamó la atención. A veces son llamadas muy acertadas, pero su valor para quien quiera comprender la obra desaparece al encontrarse mezcladas con otras de escaso relieve. Resultará de utilidad, por ello, hacer visible la estructura de los contenidos del diálogo para que el estudioso moderno pueda juzgar con fundamento el alcance y sentido de la obra. ${ }^{40}$

La estructura del Dialogus de pace está expuesta de acuerdo con las normas de la retórica y dialéctica usuales en la época, aunque la clave interpretativa se halla en una posición relativamente inusual. En concreto, hay que acudir a las páginas $79-81$, donde se inserta una enumeratio que recupera todos los puntos tratados hasta entonces, en lo que podríamos llamar primera parte (12-79). Tras ella, y antes de la "segunda parte» (82-122), se ofrecen indicaciones sobre la distribución de esta última. Y todo esto en un libro construido en forma de diálogo, tal como expresa el título, entre el rey Felipe II y el duque de Terranova, cabeza de la delegación real en la conferencia de Colonia. Como suele ocurrir en muchos diálogos renacentistas, la ficción dialógica es muy somera y abundan las tiradas de muchas páginas sin interrupción; y en el caso que nos ocupa, especialmente en boca del duque, que es quien aporta el argumento ideológico, bajo la ficción de que está trasladando al rey el contenido de un escrito sobre el acuerdo de paz que acababa de leer. ${ }^{41}$ Se presenta a continuación el esquema general de la argumentación del Dialogus de pace, tal como se puede reconstruir a partir de esa enumeratio:

\section{Preámbulo}

\section{A. Cuánta libertad religiosa debe concederse a los belgas}

Alterum est quam pacem, sive quantam in religione libertatem [...] Belgis nunc concedere debes ${ }^{42}$

A.1. Hay causas justas para nuevas concesiones

A.1.1. Reconocer el acuerdo de Gante

A.1.2. Un rey católico puede permitir el ejercicio de otra confesión en su territorio sin violar su conciencia

A.1.3. Las motivaciones del acuerdo de Gante fueron justas

A.1.4. El resultado final, en caso de seguir la guerra, es incierto

A.1.5. El daño, en caso de perder la guerra, sería gravísimo

\footnotetext{
40 Son muy útiles las reflexiones sobre el género dialógico, especialmente sobre su «naturaleza fronteriza entre lo ficticio y lo doctrinal», en Gómez 2015: 39-68.

41 Dice así el comienzo del Dialogus de pace: 9: «Accepi hisce diebus, clementissime rex, quoddam de pace hac Belgica constituenda eruditi cuiusdam viri iudicium..." (He recibido por estos días, Majestad, cierto parecer de un hombre erudito sobre el establecimiento de este acuerdo de paz para los Países Bajos ).

42 «Una cosa es qué acuerdo de paz, o cuánta libertad religiosa [...] debes conceder ahora a los belgas».
}

A.2. Es posible hacer nuevas concesiones, porque

A.2.1. Casi son idénticos los resultados de conceder y de no hacerlo

A.2.2. El servicio a la religión no será mayor usando prohibiciones

A.2.3. No habría garantías de que iban a obedecer a medio plazo

A.2.4. Prolongar la guerra haría aumentar el número de herejes en nuestros territorios y la opresión de los católicos en los suyos

A.2.5. La victoria sería a costa de grandes daños y gran impopularidad

A.2.6. Breve enumeración de otras razones

[enumeratio: 79-81]

\section{B. Qué medios hay que poner para garantizar} la paz 81-125

Alterum, quaenam commodissimae iudicandae sint rationes quibus et tibi et Belgis caveri possit, ut et ipsi constitutam pacem per Maiestatem tuam salvam et inviolatam permansuram confidant, et tu vicissim fidere possit ipsos quoque nihil adversus eam in posterum molituros ${ }^{43}$

B.1. Cuál es el modo adecuado de la concesión de libertad de conciencia

B.1.1. Los hombres fácilmente incumplen sus juramentos

B.1.2. Debate sobre la licitud de incumplir un juramento

B.1.3. El juramento no debe ser la garantía única de cumplimiento del pacto

B.1.4. Alejar las tropas extranjeras, la mejor muestra de buena voluntad

B.2. Qué precauciones pueden establecerse para que las partes respeten el acuerdo

B.2.1. Cuestiones relativas a la legislación: Juramento

Retirada de tropas

Gobernador católico y aceptable para los naturales

Respetar la elección de gobernador de las provincias del norte

Reconocer la libertad de conciencia

B.2.2. Garantías para preservar el pacto Juramento de respetar a los católicos Restitución de bienes, títulos y cargos Amnistía

Restitución de la autoridad real y de su derecho a nombrar cargos Cuantificación de las ciudades en que se autoriza culto

Las concesiones a la libertad de conciencia han de ser perpetuas

43 «La otra cosa es qué procedimientos deben juzgarse más apropiados para que tanto tú como los belgas podáis precaveros; por un lado, para que ellos confíen en que por parte de vuestra Majestad el acuerdo de paz permanecerá a salvo e intacto, y por otro, para que por tu parte tú puedas confiar también que ellos no intentarán nada en adelante contra ella». 


\section{Frente al deseo de paz y de utilidad para la Iglesia están sendos impedimentos: el odio enconado y el olvido de los remedios}

125

C.1. Contra el odio

Disculpar

Remitir el juicio a Dios

Ser conscientes de cómo también nosotros hemos suscitado odio

C.2. Poner en marcha los remedios

Formar juicios moderados sobre el proceder del adversario

Sentir en lo sucedido la voluntad o permisión de Dios

Entender que todos nos excedimos

[Quaestio de vera Ecclesia] 134-136

La falta de santidad en la vida de la Iglesia es el mayor impedimento para la concordia

\section{Conclusión}

Una vez examinada la estructura, es posible reconocer los puntos fundamentales sobre los que se vertebra el razonamiento, si bien el análisis detallado permite observar un proceso argumentativo más complejo que el reflejado en la enumeratio. En cualquier caso, la estructura bipartita es muy clara y se corresponde con dos momentos diferentes del progreso de las ideas.

El primer momento se atiene a un problema que condicionaba el sentido mismo de toda la conferencia: ¿cuál es el límite, entre la oportunidad y moralidad, hasta donde un rey católico puede permitir tener súbditos de otras confesiones religiosas, e incluso el culto público de estas últimas? La cuestión se circunscribe aquí al caso concreto de la revuelta de los Países Bajos y, en concreto, a si se podían ofrecer a los rebeldes concesiones más allá de lo contenido en el acuerdo de pacificación de Gante. ${ }^{44}$ Este acuerdo, de noviembre de 1576, había incluido la retirada de las tropas españolas y la restauración de los derechos cívicos, privilegios y libertades a su formulación previa. Según ese acuerdo, la autoridad sería restituida al rey, quien aplicaría una amnistía a todos los rebeldes, además de suprimir la persecución religiosa del período previo y sus efectos. El planteamiento inicial de Ximénez no es teórico, sino eminentemente pegado a la realidad: es preciso partir del acuerdo de Gante, puesto que el mayor fracaso de las negociaciones sería que los delegados se retiraran, en caso de ver un panorama inicial demasiado exigente. ${ }^{45}$ Entre las páginas 20 y 27 se desarrolla un discurso ficticio en que el duque planea, primeramente, hacer ver a los rebeldes la maldad de muchas de sus actuaciones, impropias en ocasiones hasta de los hombres más rudos. Luego pasa a señalar lo inapropiado de no aceptar la benevolencia del rey, como pasó en el abortado acuerdo de Breda (1575), y de presentar exigencias extemporáneas. Siguen las ofertas

44 Sobre la pacificación de Gante, véase Koenigsberger 2001: 270-272.

45 De pace: 15: "Quod si plus a se exigi intellegent quam ipsi [...] admittendum putant, [...] verisimile est ab ipsos [principibus] postulaturos ut cum bona ipsorum gratia in patriam rebus infectis redire eis liceat». a los calvinistas: conceder libertad de conciencia, mantener el culto en los lugares reconocidos por el acuerdo de Gante, otorgar un perdón general para todas las acciones violentas anteriores. A los católicos, por su parte, se ofrece el perdón del crimen de haber apoyado a un poder en mano de herejes. Concluye ofreciendo a todos, finalmente, amnistía, libertad de culto, libertad de conciencia y ausencia de tropas extranjeras. ${ }^{46}$

Volviendo al problema moral, Ximénez desarrolla a continuación la tesis de que un rey católico puede permitir el ejercicio de otra religión en su territorio. ${ }^{47}$ Aplica el concepto de la tolerancia del mal en un estado de necesidad, para evitar males mayores. ${ }^{48}$ Para ilustrarlo usa cinco ejemplos: la presencia secular de judíos en territorios cristianos, la pervivencia del paganismo durante el mandato de muchos emperadores cristianos, la tolerancia de Teodorico para con los arrianos, el trato benévolo hacia los hussitas y, por último, el Edicto Perpetuo firmado por Juan de Austria en 1577. Como condición para esa tolerancia, será preciso obtener garantías de que ser permitirá el culto católico al menos en dos ciudades de Holanda y Zelanda. ${ }^{49}$

Para justificar que existe motivo suficiente para asumir esa política de tolerancia, Ximénez se embarca en la exposición de hasta qué punto es grande el mal que acecha. Para ello, expone que el resultado de seguir la guerra es incierto y, aunque fuera con victoria, no sería sino a costa de grandes daños y sufrimientos. ${ }^{50}$ Enumera detalladamente los peligros y horrores de la guerra (38-41) y a continuación deshace con ejemplos del Antiguo Testamento (Gedeón, Josué) el argumento providencialista de que Dios debe dar la victoria a los que pugnan por Él.

Siguiendo con el principio del mal menor, trata de demostrar que existen causas justas y graves que justifican aumentar las cesiones sobre el Acuerdo de Gante, para lo que compara (52-54) los gravísimos perjuicios que se seguirían de una hipotética derrota con los inevitables perjuicios que se derivarían de las cesiones en un acuerdo de paz.

La siguiente sección, desarrollada con gran amplitud, es la de los motivos que existen para tolerar un nivel

46 De pace: 26-27: "Habituri per illam [pacem] sunt omnium quae in provinciis Maiestatis tuae gesta sunt perpetuam oblivionem; habituri sunt eam quam optant in Hollandia et Zelandia religionem; habituri etiam aliis in locis omnibus integran conscientiarum libertatem; provincias denique suas habituri sunt ab omni externo milite in posterum liberas".

47 De pace: 29: «...primum dubitationi tuae satisfaciam, in qua sentire videris nullo modo absque peccato ac Dei indignatione te publicum posse tolerare alterius quam Catholicae religionis in ditionibus tuis exercitium» (primero satisfaré tu duda, según la cual parece que sientes que de ninguna manera puedes tolerar en tus territiorios la práctica pública de otra religión diferente de la católica sin incurrir en pecado y en el enojo de Dios). Sobre la permisión de dos religiones en el reino, véase más abajo, al tratar de la Religionsfriede.

48 La cuestión de la tolerancia ha suscitado un vivo debate desde finales del siglo pasado a raíz de la propuesta de enfrentarla conceptualmente a la concordia, según Turchetti 1984: 407-425, tesis reiterada en Turchetti 1991: 15-25. Esa propuesta, hoy ampliamente difundida, se critica por reduccionista en Gilly 1998: 144-166, 147-151. Fiel seguidora de la línea de Turchetti se muestra, por ejemplo, Urbinati 2014: 130-169.

49 Sobre el intento fallido de conseguir la convivencia de cultos, $c f$. Goosens 1997: 121-125.

50 De pace: 37: «...demonstrandum prius nobis est admodum ancipitem et dubiam nobis haberi debere huius tam prolixi et calamitosi belli, si id forte paci praeferendum esse censeamus, nostram victoriam». 
más elevado de libertad. Se señalan seis, expuestos con amplitud creciente: 1 . es mínima la diferencia de hecho entre tolerar y no tolerar (55); 2. el peligro para la religión católica es equiparable en ambos casos (56); 3. siendo el número de los rebeldes tan grande, no sería esperable que cumplieran durante mucho tiempo con lo pactado en un acuerdo restrictivo (58); 4. con un acuerdo de paz permisivo se evitarían otros males para la religión católica (59); 5 . la victoria militar, si se obtuviera, sería a costa de grandes males y de gran impopularidad (62).

Tras todo este desarrollo, Ximénez considera haber llegado (77) a la solución del problema moral planteado desde la página 29 , concluyendo que la pacificación mediante nuevas cesiones no es injusta ni inmoral, sino que conlleva beneficios para todos y la evitación de grandes males. ${ }^{51}$ Con ello concluye la primera parte de la obra.

El segundo momento argumentativo (a partir de la página 81) se apoya sobre la convicción previamente establecida de que la negociación del nuevo acuerdo de paz puede llevar a cabo más concesiones a los rebeldes en materia religiosa. Consiste en determinar cómo se garantiza el cumplimiento por ambas partes del acuerdo al que se llegue.

El motivo de la necesidad de establecer garantías surge de la experiencia de la inconstancia de los hombres en el juramento prestado (82). Una vez anotado este hecho de experiencia, se abre una cuestión moral, acerca de la licitud de incumplir el juramento prestado en determinadas circunstancias (84-100). A lo largo de la argumentación se resume en boca del Duque de Terranova la casuística de la teología moral del momento, hasta el punto de permitirse ironizar al respecto. ${ }^{52} \mathrm{El}$ motivo de la gran extensión de este apartado es la acusación, muy difundida en los panfletos calvinistas, de que los católicos no se consideraban obligados por un juramento prestado a un infiel o a un hereje..$^{53}$ Ximénez sale al paso de ello, pensando en calmar en este punto a sus lectores. Tras la exposición teórica, cambia el registro y pasa a relatar varios exempla que dejan clara su postura contraria a cualquier incumplimiento: el famoso caso de Marco Atilio Régulo, que volvió a Cartago cumpliendo su palabra, aunque sabía que le aguardaba una muerte atroz; el del emperador Carlos V, que respetó el salvoconducto concedido a Lutero en la Dieta de Worms; y el de Josué, que respetó a los gabaonitas aunque le habían engañado. La conclusión es que, si bien nunca es admisible hacer algo malo, sin embargo puede permitirse y tolerarse algo que dé ocasión a otros de hacer un mal, si es que hay

51 De pace: 77: «...fateri sane cogor, et quidem cum gravi animi mei moerore, eam [pacem] non in speciem modo, sed revera deformem et tua Maiestate prorsus esse indignam; alia tamen ex parte, allatas rationes ante oculos habens, iustam, aequam, reipublicae salutarem et, quia sine verisimili atrocissimorum malorum periculo repudiari non potuit, Deo Optimo Maximo gratam esse certissime confido».

52 De pace: 90: «...videor enim mihi posteaquam hisce diebus virum illum diligenter audivi, in hoc saltem argumento quadam ex parte factus esse theologus» (...en efecto, después de haber escuchado atentamente a aquel gran hombre estos días, me parece que, al menos en esta cuestión, me he vuelto un poco teólogo).

53 Una recopilación de amplia literatura polémica anticatólica sobre el principio "haereticis non est praestanda fides» puede verse en Geurts 1956: 171-174. Entre ellos destaca la extensa refutación por parte católica escrita en fecha muy cercana al Dialogus de pace por Molanus 1584. una causa justa para ello54; y el respeto del juramento es una de esas causas. A fin de cuentas, el incumplimiento de lo jurado causa el embrutecimiento de la sociedad, la deshonra del perjuro y graves males de orden práctico. ${ }^{55}$

De aceptar el principio contrario (la licitud del perjurio en determinados casos) nace, de hecho, el que los herejes se sientan justificados para incumplir los acuerdos o para firmar acuerdos a la ligera, sin intención de atenerse a lo pactado.

Ante esa situación de hecho, se aconseja al rey (103) que establezca una serie de garantías de cumplimiento del pacto que ahora busca, más allá del juramento, no sin antes reiterar que la mejor señal de buena voluntad, destinada a recuperar la confianza de sus súbditos, es la retirada de las tropas extranjeras. Las garantías son en ambos sentidos, pues tanto los sublevados como el rey han de llevar a cabo acciones que contribuyan a consolidar la paz, porque todos perciban claramente que es mejor esa situación que la continuación de la guerra. La primera garantía es el juramento por ambas partes. ${ }^{56}$ A continuación, se exponen (107) las medidas que corresponden al rey: retirar las tropas ${ }^{57}$, nombrar un gobernador de los Países Bajos creíble para ambas partes (pero católico) ${ }^{58}$, confirmar la elección del gobernador de las provincias del norte ${ }^{59} \mathrm{y}$, por último, respetar la libertad de conciencia, de manera que en todas partes cada persona pueda profesar su fe con seguridad y optar a cargos públicos, independientemente de su confesión. ${ }^{60}$

Por el lado de los rebeldes, las precauciones que se deben tomar son (110): en primer lugar, el juramento, pero reforzado en este caso con la suscripción de los ministros reformados, para que no quede resquicio alguno sobre el que argumentar que fue un acto inválido; de hecho, debe contener explícitamente una cláusula referente al respeto al culto católico en esas provincias. ${ }^{61}$ La segunda es la

54 De pace: 93: "Satis ergo intelligitur, quamvis id quod per se crimen est ne propter totius quidem orbis salutem ullo modo sit committendum, aliquid tamen absque peccato permitti et tolerari posse, quod peccati occasionem aliis praebeat quodque in non leve religionis incommodum redundaturum verisimile sit, si modo iusta quaedam (quod fieri non raro potest) permittendi causa subsit».

55 De pace: 100: "Videmus igitur [...] et summam huius criminis atrocitatem atque adhaerentis ipsi infamiae et tam publicorum quam privatorum, quae ipsum consequuntur, incommodorum magnitudinem».

56 De pace: 107: "Prima itaque cautio Maiestati tuae cum subditis communis sit, ipsum utrinque praestandum iuramentum».

57 De pace: 107: «Secunda est omnium militarium copiarum exautoratio et totius exercitus dimissio et [...] ex harum ditionum finibus abitio".

58 De pace: 107: "Tertia, ut talis in his ditionibus relinquatur supremus gubernator et generalis Maiestatis tuae vicarius, qui propter tuam quidem securitatem sit vere atque ex animo Catholicus, propter subditos autem eiusmodi qui non possit ab ipsis tanquam sibi suspectus vel tanquam novas res adversus ipsos moliturus merito recusari».

59 De pace: 107-108: "Quarta, ut Hollandia et Zelandia suum in posterum nominent gubernatorem, quem Maiestas tua confirmare debeat, reiicere non possit...».

60 De pace: 108: "Quinta ac postrema cautio sit, quia liberae futurae sunt et in Hollandi et Zelandia Catholicorum et in aliis provinciis Protestantium conscientiae, hoc est, quia omnes ubique tuto profiteri poterunt, cuius sint religionis, ut nemo religionis nomine vel in his vel in illis provinciis inidoneus ad senatoris vfel consiliarii vel cuiuscunque alterius magistratus munus gerendum repelli queat».

61 De pace: 112: «Hi ergo praecipue tum polliceri et iurare cogantur sese contra Papisticam (ut ipsi vocant) religionem et contra Papistarum sacra nihil in his provinciis molituros aliud quam quod huius foederis conditionibus illis permittitur». 
restitución, por parte de ambos bandos, de bienes y títulos, civiles y eclesiásticos, a la situación previa a la guerra, así como la permisión para los católicos de acceder a los cargos públicos. ${ }^{62}$ Esta medida incluye una amnistía total por ambas partes, que ya se había mencionado antes. ${ }^{63} \mathrm{El}$ sentido último de esta medida es que los rebeldes sientan que la otra parte ha quedado despojada de la capacidad de atacar y, por lo tanto, que la paz es sostenible. Una vez establecido lo anterior, la tercera garantía que deberían cumplir los rebeldes es la restitución de la autoridad real y de su derecho a nombrar cargos, respetando los privilegios locales; se trata de retornar a la situación legal previa al levantamiento. ${ }^{64}$ La cuarta medida es la determinación de las ciudades en las que se autoriza el culto de la otra confesión: en el sur, cuántas y cuáles admitirán el culto reformado, y en el norte, qué dos ciudades serán de culto católico. ${ }^{65}$

Una vez completada la exposición de las garantías y cautelas, se trata la cuestión (122) de si esas concesiones a la libertad de conciencia han de ser perpetuas o solo hasta la siguiente dieta. Se responde que la estabilidad de la paz reclama que esas concesiones sean permanentes, no pendientes de renovación o revisión.

Estableciendo un giro respecto a lo dicho, en la página 124 se plantea si, antes que ese reconocimiento de ciudades con culto diferente, sería mejor una "paz religiosa» (en alemán Religionsfriede, escribe Ximénez). ${ }^{66}$ Con ello se trataría de permitir en cualquier lugar el culto de cualquier confesión reconocida, con tal de que haya un mínimo de fieles. Ximénez recomienda esta fórmula como preferible, llevado por dos motivos: en primer lugar, se facilitaría a muchos más católicos el acceso al culto; en segundo lugar, la experiencia demuestra que la prohibición es el caldo de cultivo ideal para las sectas. Además, quedaría a la vista que la corrupción de la que acusan a los católicos no se da en menor medida en los ministros reformados, allí donde se ha impuesto el protestantismo.

Aquí concluye, prácticamente, la argumentación respecto a cómo debe conducirse la negociación de parte del monarca en la Conferencia de Colonia. Pero todavía quedan unas cuantas páginas, en las que se examina un problema amenazante. En efecto, a partir de la página 125 se

62 De pace: 112: "Secunda cautio est ut quotquot omnibus hisce bellis tuas partes secuti sunt [...] non bona tantum sua hoc bello ipsis erepta, si reddi queant, recuperent, verum etiam honoribus, dignitatibus, praefecturis, magistratibus atque officiis quibus hactenus caruerunt restituantur».

63 De pace: 112-113: "Statuetur utrinque omnium gestorum atque hoc bello innovatorum oblivio».

64 De pace: 118: "Tertia pro Maiestate tua cautio est ut plene tibi reddatur omnis tua prior authoritas atque omne ius (quod tamen veteribus harum ditionum privilegiis non adversetur) in nominandis in posterum et creandis singularum provinciarum gubernatoribus atque in conferendis omnibus et quibuscunque dignitatibus et officiis».

65 De pace: 120: "In quarta et postrema cautione, et de nominibus et numero agetur illarum urbium, in quibus extra Hollandiam et Zelandiam conciones et sacra Calviniana celebrabuntur, et duae illae in Hollandia et Zelandia in quibus suae quoque religionis exercitium habituri Catholici sunt, nominabuntur».

66 En este punto Ximenius se acerca a la postura de Castellio 1562, «laisser les deux religions libres» (página 56). En fecha más cercana a Ximenius (1567) lo había aplicado a los Países Bajos un español, Corro 1567, cf. Miiiv: «vostre Maiesté pourra en bonne conscience maintenir en ses terres \& protection deux sortes de religion, accordantes toutes deux à receuoir IESVS CHRIST pour leur redempteur...". plantea que los dos deseos que deben guiar al rey son el de la estabilidad de la paz y el del provecho de la Iglesia. Ahora bien, contra estos magnánimos deseos se levantan sendos impedimentos. Frente a paz resulta especialmente dañino el odio enconado por ambas partes, y frente al provecho de la Iglesia, el desprecio de los remedios proporcionados por Dios. ${ }^{67}$

Ante la realidad del odio, expone, es preciso el ejercicio generoso de disculpar los agravios del contrario. Por otra parte, aunque los crímenes sean innegables, debemos remitir el juicio a Dios, que los ha permitido, en vez de tomarnos la justicia por nuestra mano (y para ello menciona los ejemplos del patriarca José, de los apóstoles predicando el perdón y, por último, de Cicerón en una larga cita del Pro Ligario). Para luchar contra la inclinación al odio también es preciso ser conscientes de que también nosotros hemos suscitado odio con nuestras malas acciones.

El otro problema se concreta en no aprovechar los remedios proporcionados por Dios; y se desarrolla este punto en paralelo al del odio, pues se presentan maneras para poner en práctica los tres aspectos señalados. Para disculpar, hay que formar juicios moderados sobre el proceder del adversario; para remitir el juicio a Dios, se debe empezar sintiendo en lo sucedido la voluntad o permisión de Dios, pues parecería inverosímil que personas normales pudieran llegar a los excesos cometidos. Por último, hay que esforzarse por entender que todas las partes cometieron excesos.

Ese es el ejemplo de Cristo (131) que, mientras sufría la mayor de las injusticias, disculpaba a sus verdugos por su ignorancia; esa actitud pasó a sus apóstoles, y nada impide que los católicos la tengan hacia los luteranos y los calvinistas, tanto más cuanto que estos obran pensando que lo hacen en servicio de Dios. ${ }^{68} \mathrm{Y}$, a la vista de las malas costumbres que pululan en la Iglesia católica, no es raro que estas hayan suscitado la repugnancia de personas de fuerte sentido religioso; de manera que los católicos tienen que ser conscientes de haber sido motivo de escándalo y, en muchos casos, de no haber sido ajenos al origen de las nuevas confesiones. En este punto se introduce una última cuestión (134-139), que podríamos llamar de vera Ecclesia. En primer lugar, repasa algunos argumentos de credibilidad de la Iglesia católica, tanto afirmativos (la difusión entre pueblos de toda clase; la autoridad estable durante siglos; la sucesión apostólica; el nombre mismo de católica) como negativos (si no fuera la verdadera Iglesia, no se justificaría

67 De pace: 126: «Nam quod ad nos attinet, duo profecto nobiscum afferimus validissima contra utrumque bonum impedimenta: contra pacis quidem diuturnitatem, truculentissimum utrinque in adversarios odium, contra Catholicae vero religionis restitutionem, omnium eorum remediorum, quibus ad Ecclesiam haeretici revocandi essent, nimis altam oblivionem».

68 De pace: 126-127: «Nam si Christus in illo omnium teterrimo [...] facinore talem agnoscere non dubitavit crucifigentium ipsum ignorantiam, quae peccatum eorum imminuere quaeque proinde veluti causa quaedam cur venia digniores essent Patri coelesti proponi posset; si iidem in omnibus Apostolorum et fidelium persecutoribus, quod obsequium se Deo praestare arbitrantur, testimonium praebere non gravatur; si Paulus ludaeorum quoque in Christi odio et fidelium persecutione zelum commendare non dubitat, nihil certe nos amplius prohibere potest quin clementisime de plerisque Calvinianis et Lutheranis sentiamus, si Christi, inquam, et Apostolorum imitatores esse volumus». 
la pervivencia durante más de un milenio, la asistencia constante del Espíritu Santo, la victoria contra las puertas del Infierno, etc.). A continuación, pasa a deshacer los argumentos de la parte contraria; por ejemplo, reprocha a los protestantes que se apoyen en los Padres de la Iglesia, cuando estos aceptaron a menudo doctrinas que los protestantes critican en los católicos; o también, recuerda que la corrupción que los protestantes denuncian entre los católicos se comprueba también entre los protestantes, e incluso peor: pululan las sectas, domina la vulgaridad y las injurias, actúan violentamente contra personas y cosas...

El cierre de la cuestión sobre qué hacer se eleva de la acción humana al plano sobrenatural (141): para alcanzar la tan deseada paz y el bien de la Iglesia, es precisa, más que otra cosa, la oración de súplica, la acción divina en bien de sus fieles. ${ }^{69}$ Se recuerda a continuación que la cuestión tratada era la de la negligencia de todos en aplicar los remedios (141143), pero con una formulación que no es mera enumeratio retrospectiva, sino que ofrece un listado de acciones mucho más concretas que las de antes; se menciona la renuencia a suprimir devociones abusivas o a acceder a demandas que no dañan la fe católica (con posible alusión, por ejemplo, a la comunión sub utraque specie); se censura la pereza intelectual para generar argumentos convincentes para la otra parte; se mencionan las posibilidades de un concilio general, de sínodos regionales, de dietas, de escritos de particulares. Todo esto se ha hecho, pero quizá sin el empeño intelectual y espiritual que el problema requería.

Acaba, por fin, con una imprecación al rey para que, con la ayuda de Dios, ponga por obra lo expresado en este diálogo, para bien propio y de sus desventuradas provincias de los Países Bajos (143-144).

\section{LAS IDEAS DE XIMÉNEZ}

El anónimo varón que en la ficción aportó argumentos al Duque de Terranova para facilitar el acuerdo se muestra en todo momento bien enterado de la situación. No faltan las referencias a la violencia de las tropas españolas, especialmente dolorosa en el saco de Amberes de 1576; tampoco a la furia iconoclasta calvinista, tan característica del Wonderjaar. Está al tanto de los intentos previos de alcanzar acuerdos, como la negociación de Breda (1575) o la pacificación de Gante (1577). No propone un planteamiento equidistante entre las partes en conflicto, sino que desde la primera línea queda claro que su objeto es colaborar con la delegación real, frente a la de los Estados Generales. En cierto modo, el planteamiento es que debe buscarse el acuerdo a toda costa, incluso aunque la otra parte no ponga de su parte lo esperable para llegar a él. En este sentido, no puede afirmarse que el libro peque de inocente o de desconocimiento de la materia.

La línea argumentativa principal es la de la necesidad del reconocimiento de la libertad de conciencia y culto para todos los súbditos, como medida clave para el éxito

69 De pace: 140-141: "Reliquum ergo nunc duntaxat esset ut quo pacto cum Deo nostra movenda sit manus ad pacem hanc Catholicae quoque religioni in his ditionibus utilem reddendam, Maiestati tuae vel explicare vel indicare conarer». de la negociación. Sin ello, y ante el hecho de que no es realista plantear la extirpación de la confesión calvinista en Zelanda y Holanda, todos los empeños resultarán inútiles. El asentamiento de la paz se ha de apoyar en varias actuaciones, que corresponden a ambas partes: en primer lugar, un juramento detallado y firmado por muchos actores, no solo los delegados; en segundo lugar, una amnistía general en ambas partes, sin exclusiones; en tercer lugar, la restitución de bienes y privilegios a su situación previa al estallido de la violencia; cuarto, la desaparición de las tropas extranjeras; por último, la reconciliación de las partes, sanando los odios que se han generado en trece años de guerra. ${ }^{70}$

Es preciso señalar que buena parte de esta argumentación conecta con el contenido de los escritos políticos de Fadrique Furio Ceriol, humanista que ya había estado en relación con Ximénez en Lovaina, como parte del conventículo filoprotestante denunciado por fray Baltasar Pérez y mencionado al comienzo de este estudio. ${ }^{71}$ Furio, una vez escapado de la cárcel y refugiado en Colonia, había tenido que aceptar la repatriación a la península ibérica como transacción para evitar la acción de la justicia sobre sí. Aceptó renunciar a publicar varios libros que tenía listos en perjuicio de la monarquía y emprendió el regreso, que se produjo a finales de 1563 y conllevó un tiempo de libertad supervisada, al servicio de diferentes nobles por orden del rey. ${ }^{72}$ Pasarían nueve años hasta que el rey volviera a confiar en él: en 1573 acompañó al nuevo gobernador de los Países Bajos, don Luis de Requesens y Zúñiga, como sucesor del duque de Alba. Permaneció en la zona hasta 1577 y actuó como informador, consejero y diplomático no oficial.

Quizá anterior a la partida de Furio de España es un primer escrito suyo sobre la situación política de los Países Bajos, Ilamado Remedios dados por Fadrique Furio Ceriol a su Majestad para el sosiego de las alteraciones de los Países Bajos de los Estados de Flandes; en él se propone al rey la clemencia como la característica más destacada del buen gobernante. ${ }^{73}$ El segundo, escrito en 1574 ya sobre el terreno y titulado Discurso sobre la quiete de estos estados, es una adaptación reducida de los Remedios, dirigida un «ilustrísimo señor». ${ }^{74}$ Un escrito, posiblemente de 1575, que Furio hizo llegar al príncipe de Orange por mediación de Jean Matal, el amigo íntimo de Ximénez, con el título Articuli, seu pacis inter Philippum Hispaniarum regem et Hollandiae Zelandiaeque confoederatos conciliandae capita decem, Auriaco principi per Metellum, Furii Caeriolani nomine transmissa, es una enumeración de diez puntos de compromiso sobre los que asentar la paz. ${ }^{75}$ Estas tres obras, más otro anónimo titulado Tres puntos principales y útiles

\footnotetext{
70 Un primer análisis de la obra puede leerse en Heuser 2013: 405-407.

71 Es amplia la bibliografía sobre Furio (mejor que Furió). Una síntesis, aunque matizable, en Pérez Durá 2012: 324-327. También se expone su perfil biográfico en Ferragut Domínguez y Grau Codina 2016: 39-95.

72 Toda la sucesión de acontecimientos se expone detalladamente en Méchoulan y Almenara Sebastiá 1996: 13-43, 27-33.

73 Esta propuesta de datación procede de una comunicación de Miquel Almenara, que prepara la edición del segundo volumen de las Obras Completas de Furio, donde se publicarán todos estos documentos.

74 Colección de documentos inéditos para la historia de España 1892: vol. 102, 473-476.

75 Había pasado desapercibido hasta Gilly 1985: 198-199, a pesar de estar impreso dos veces, en Colonia, 1583 y en Basilea, 1586.
} 
para la buena dirección del estado de las cosas del País Bajo y atribuido a Furio $^{76}$, forman un pequeño corpus de escritos sobre la paz que presentan planteamientos muy abiertos y tolerantes.

Desde el punto de vista del Dialogus de pace, es preciso señalar que Ximénez debió de tener acceso a estos escritos de Furio, o al menos a alguno de ellos; con toda probabilidad, a los Articuli, pues el portador fue Jean Matal, como se ha dicho, y su brevedad hacía fácil su copia. Por otra parte, sabemos que Furio pasó algún tiempo en Colonia en 1575, con lo que pudo reunirse con su viejo amigo Ximénez. ${ }^{77} \mathrm{Si}$ se lee el Dialogus de pace junto con los escritos de Furio, se apreciará la coincidencia en muchos conceptos, aunque no en todos ni, desde luego, en calcos textuales. ${ }^{78}$ Entre lo más patente, en la página 112 del Dialogus es reconocible el articulus IIII de Furio, que propone la restitución total, no solo de bienes, sino de títulos y cargos. El articulus $V$, sobre el respeto a los acuerdos y su ratificación por muchos, se recoge en la página 110 . El articulus VII se refiere a la partida de las tropas extranjeras, asunto este que se reitera en el Dialogus $\left(106,108\right.$, etc.)..$^{79}$ Nótese que todas estas coincidencias se señalan en la misma sección central del Dialogus. Además de ello, es preciso examinar también los otros escritos de Furio, pues en ellos se reiteran muchos de los conceptos y se exponen con más amplitud; es el caso, por ejemplo, del "décimo remedio» que se propone en el Discurso sobre la quiete de estos estados: «asegurarles sus ánimos, confirmándoles todas sus leyes antiguas, fueros, privilegios y loables costumbres», y que coincide con el principio ad priora iura revocari, en Dialogus la página 119.

Cuando se convocó la Conferencia de Colonia y, después, cuando Ximénez redactó su escrito, Furio ya estaba de vuelta en España. Sin embargo, ambos personajes tenían intereses muy cercanos en cuanto a la paz y la gestión política en los Países Bajos; también compartían relaciones y un pasado amistoso. Es razonable, por tanto, esta presencia del pensamiento político de Furio, y no solo de sus escritos, en el Dialogus de pace, sin que esto exima a los investigadores de buscar otras fuentes. Sin embargo, y de modo contrario a lo que suele observar en Furio, la neta conexión entre moral, religión y política que se observa en el escrito de Ximénez permite descartar cualquier planteamiento maquiavélico, e incluso algunos pasajes se perciben como una oposición directa a ideas de /I principe, como, por ejemplo, cuando se encarece la necesidad de cumplir los compromisos a toda costa (De pace, 100). ${ }^{80}$

La cercanía personal y conceptual entre Furio y Ximénez no empaña nuestro acercamiento a este último; antes bien, permite comprender mejor la matriz en la que se generan sus ideas. Igualmente debería decirse que parte

\footnotetext{
76 Se encuentra en la Collection Favre de Ginebra, vol. XL, 217-220 y su atribución a Furio se debe a Gilly 1985: 200.

77 Méchoulan y Almenara Sebastiá 1996: 38.

78 De todos modos, llama la atención la coincidencia en el uso del verbo exauctoro («licenciar tropas»), poco frecuente, en el articulus VII y en De pace: 107 , véase nota 37.

79 Por otra parte, estos cuatro aspectos ya se habían presentado unidos en De pace: 26-27, cf. nota 29.

80 Sin embargo, Maquiavelo era conocido y usado parcialmente por humanistas cercanos a Ximénez, como Felipe de la Torre, Sebastián Fox Morcillo y el señalado Fadrique Furio Ceriol; cf. Truman 1999: passim; y Ascia 1999: 551-584.
}

de los conceptos pueden apropiarse también a Jean Matal, conocedor de los entresijos de la publicación de esta obra, seguramente porque intervino en ella. Aparte de la posibilidad de que también haya influido Antonio del Corro, esta obra de Ximenius se inserta en un círculo irenista establecido en Colonia y perennemente sospechoso para los representantes de la ortodoxia religiosa, a pesar de que ellos siempre permanecieron en el seno de la Iglesia católica.

El examen detallado que se ha presentado del contenido del Dialogus de pace, obra habitualmente ausente en los análisis de las propuestas políticas pacificadoras en el contexto bélico de la Guerra de los Ochenta Años, proporciona a la comunidad investigadora un instrumento nuevo sobre el que apoyarse para ulteriores trabajos. Asociándolo al corpus de textos políticos de Fadrique Furio Ceriol, se establece un primer marco para entender la postura política, alejada de cualquier actitud inmovilista o abstracta. También ha quedado de manifiesto que la apuesta de Ximénez por la paz se basa sobre el respeto de los principios morales cristianos y sobre la convivencia religiosa entre los súbditos de diferentes confesiones, como bases ineludibles para la reconciliación. Se ofrece con todo esto un nuevo elemento de juicio a la hora de estudiar el pensamiento político por parte de españoles en la época que está a punto de alumbrar a Justo Lipsio y Hugo Grocio.

\section{MANUSCRITOS CITADOS}

Bibliothèque de Genève, col. Eduard Favre, vol. XL. Bibliothèque Nationale de France, col. Dupuy 348. British Library, Lansdowne ms. 38.

\section{BIBLIOGRAFÍA}

Analecticorum Belgorum pars prima. 1772. Leiden: van Hoogeveen.

Arndt, J. 1998. «Die kaiserlichen Friedensvermittlungen im spanischniederländischen Krieg 1568-1609». Rheinische Vierteljahrsblätter 62: 161-183.

Ascia, L. D’. 1999. «Fadrique Furió Ceriol fra Erasmo e Machiavelli». Passato e presente 47: 551-584.

Castellio, S. 1562. Conseil à la France desolée. s. I., s. i.

Colección de documentos inéditos para la historia de España. 1892. Madrid: Rafael Marco.

Correspondance du Cardinal de Granvelle (1565-1586). Bruselas: F. Hayez. 12 vols. [E. Poullet y Ch. Piot (eds.)].

Corro, Antonio del. 1567. Lettre envoyée a la Maiesté du Roy des Espaignes \&c. notre Sire. Par laquelle un sien treshumble subiect lui rend raison de son departement du Royaume d'Espagne, \& presente à sa Ma[iesté] la confession des principaux poinctz de nostre Religion Chrestienne: luy montrant les griefves persecutions, qu'endurent ses subiets du Pais bas pur maintenir ladite Religion, \& le moyen duquel sa Ma[iesté] pourroit user pour y remedier. [Amberes: Gillis Coppens van Diest].

De Vries de Heekelingen, H. 1923. Correspondence de Bonaventura Vulcanius pendant son séjour a Cologne, Genève et Bâle (15731577). La Haya: M. Nijhoff.

Díaz Rodríguez, A. J. 2016. «El sistema de agencias curiales de la Monarquía Hispánica en la Roma pontificia». Chronica Nova 42: 51-78.

Fagel, R. P. 2015. "La Nación de Andalucía en Flandes: separatismo comercial en el siglo XVI», en J. J. Iglesias Rodríguez, R. M. Pérez García y M. F. Fernández Chaves (eds.), Comercio y cultura en la Edad Moderna: 339-352. Sevilla: Universidad de Sevilla. 
Ferragut Domínguez, C. y Grau Codina, F. 2016. «La praxis de la retórica en la obra de Fadrique Furio Ceriol», en L. von der Walde Moheno (ed.), Retórica aplicada a la literatura medieval y de los siglos XVI y XVII: 39-95. Ciudad de México: Grupo Destiempos.

Gachard, M. 1851. Correspondence de Philippe // sur les affaires des Pays-Bas. Bruselas: C. Muquardt.

García Pinilla, I. J. 1997. «Fuentes para una edición del epistolario de Pedro Jiménez (Petrus Ximenius, 1514?-1595)», en R. Villena Espinosa (ed.), Ensayos humanísticos. Homenaje al Profesor Luis Lorente Toledo: 179-207. Cuenca: Univ. Castilla-La Mancha.

Geurts, P. A. M. 1956. De Nederlandse Opstand in de pamfletten 15661584. Nimega: Centrale Drukkerij.

Gilly, C. (en prensa). «El influjo de Sébastien Castellion sobre los heterodoxos españoles del siglo XVI», en M. Boeglin y D. Kahn (eds.), Recepción de la Reforma y disidencias religiosas en la Península ibérica el siglo XVI. Madrid: Casa de Velázquez.

Gilly, C. 1985. Spanien und der Basler Buchdruck bis 1600. Ein Querschnitt durch die spanische Geistesgeschichte aus der Sicht einer europäischen Buchdruckerstadt. Basilea-Frankfurt a/Main Helbing \& Leichtenhahn.

Gilly, C. 1998. «Sebastiano Castellione, l'idea di tolleranza e I'opposizione alle politica di Filippo II». Rivista storica italiana 110: 144-166.

Gómez, J. 2015: «El lugar del diálogo en el sistema literario renacentista». Etiópicas. Revista de las Letras Renacentistas 11: 39-68.

Goosens, A. 1997. Les inquisitions modernes dans les Pays-Bas meridionaux, 1520-1633. Bruselas: Editions de l'Université de Bruxelles.

Heuser, P. A. 2003. Jean Matal, Humanistischer Jurist und europäischer Friedensdenker (um 1517-1597). Colonia: Böhlau.

Heuser, P. A. 2013. "Kaspar Schetz von Grobbendonk oder Pedro Ximénez? Studien zum historischen Ort des 'Dialogus de pace' (Köln und Antwerpen 1579)», en G. Braun y A. Strohmeyer (eds.), Frieden und Friedenssicherung in der Frühen Neuzeit. Das Heilige Römische Reich und Europa. Festschrift für Maximilian Lanzinner: 387-411. Münster: Aschendorff.

Janssens, G. 1993. «Pacification générale ou réconciliation particulière? Problèmes de guerre et de paix aux Pays-Bas au début du gouvernement d'Alexandre Farnèse (1578-1579)». Bulletin de I'Institut Historique de Rome 63: 251-278.

Koenigsberger, H. G. 2001. Monarchies, States Generals and Parliaments. The Netherlands in the fifteenth and sixteenth centuries. Cambridge: Cambridge University Press.

Losada Málvarez, J. C. 2007. Los generales de Flandes: Alejandro Farnesio y Ambrosio de Spínola, dos militares al servicio del imperio español. Madrid: La esfera de los libros.

Maczkiewitz, D. 2005. Der niederländische Aufstand gegen Spanien (1568-1609), Eine kommunikationswissenschaftliche Analyse. Münster-New York: Waxmann.

Méchoulan, H. y Almenara Sebastiá, M. 1996. «Elementos históricos y cronológicos para una biografía», en F. Furió Ceriol [H. Méchoulan y J. Pérez Durà (eds.)], Obra completa I. El consejo y consejeros del príncipe. Bononia: 13-43. Valencia: Alfons el Magnànim.

Meshov, A. 1638. De vita, moribus et obitu admodum reverendi \& eximii viri Caspari Ulenbergii. Colonia: Kreps, Officina Quenteliana.

Miraeus. A. 1649. Bibliotheca ecclesiastica, Pars altera. Amberes: Jacobus Mesius.

Molanus, J. [Jan Vermeulen] 1584. De fide haereticis servanda. Colonia: Godfried Kempen.
Pérez Durá, F. J. 2012. «Furió Ceriol, Fadrique», en J. F. Domínguez Domínguez (ed.), Diccionario biográfico y bibliográfico del humanismo español (siglos XV-XVII): 324-327. Madrid: Ediciones Clásicas.

Puraye, J. 1950. Dominique Lampson, Humaniste, 1532-1599. Lieja: Desclée de Brouwer.

Schepper, H. de 1998. «Un catalán en Flandes: don Luis de Requesens y Zuñiga, 1573-1576». Pedralbes: Revista d'historia moderna 18 (2): 157-167.

Schepper, H. de 2002. "Los Países Bajos y la Monarquía Hispánica. Intentos de reconciliación hasta la tregua de los Doce años (15741609)», en M. Herrero Sánchez y A. Crespo Solana (eds.), España y las 17 provincias de los Países Bajos: una revisión historiográfica (XVI-XVIII): vol. 1, 325-354. Córdoba: Universidad de Córdoba.

Schilling, A. 1961. Matricule de I'Université de Louvain. Bruselas: Kiessling \& Imbreght.

Soen, V. 2012. Vredehandel Adellijke en Habsburgse verzoeningspogingen tijdens de Nederlandse Opstand (1564-1581). Amsterdam: Amsterdam University Press.

Stensland, M. 2012. Habsburg Communication in the Dutch Revolt. Amsterdam: Amsterdam University Press.

Tellechea Idígoras, J. I. 1963. «Españoles en Lovaina en 1551-8. Primeras noticias sobre el bayanismo». Revista española de teología XXIII: 21-45.

Tellechea Idígoras, J. I. 2000. «Españoles en Lovaina en 1557», en W. Thomas y R. A. Verdonk (eds.), Encuentros en Flandes. Relaciones e intercambios hispanoflamencos a inicios de la Edad Moderna: 133156. Lovaina-Soria: Leuven University Press-Fundación Duques de Soria.

Torrencio, L. 2007. Correspondencia con Benito Arias Montano. Alcañiz-Madrid: Instituto de Estudios Turolenses-CSIC. [L. Charlo Brea (ed. y trad.)].

Truman, R. 1993. "Jean Matal and His Relations with Antonio Agustín, Jerónimo Osório da Fonseca and Pedro Ximenes», en M. H. Crawford (ed.), Antonio Agustín between Renaissance and Counter-Reform: 247-263. Londres: Warburg Institute.

Truman, R. 1998. «Justus Lipsius, Arias Montano and Pedro Ximenes». Bulletin de l'Institut Historique Belge de Rome 68: 367-386.

Truman, R. 1999. Spanish treatises on government, society and religion in the time of Philip II: the "De regimine principum» and associated traditions. Leiden: Brill.

Turchetti, M. 1984. Concordia o Tolleranza? François Baudoin (15201573) e $i$ «Moyenneurs». Ginebra: Droz.

Turchetti, M. 1991. «Religious concord and political tolerance in sixteenth and seventeenth-century France». Sixteenth Century Journal 22: 15-25.

Urbinati, N. 2014. "Half-Toleration: Concordia and the Limits of Dialogue», en A. Stepan y Ch. Taylor (eds.), Boundaries of Toleration: 130-169. Nueva York: Columbia University Press.

Van De Schoor, R. 2011. "Georgius Cassander: Searching For Religious Peace In His Correspondence (1557-1565)», en J. de Landtsheer (ed.), Between Scylla and Charybdis: Learned Letter Writers Navigating the Reefs of Religious and Political Controversy in Early Modern Europe: 127-147. Leiden: Brill.

Van Gelderen, M. 1992. The Political Thought of the Dutch Revolt 15551590. Cambridge: Cambridge University Press.

VD16. 1579. Verzeichnis der im deutschen Sprachbereich erschienenen Drucke des 16. Jahrhunderts. Disponible en: www.vd16.de. 